\title{
Control of diabetes mellitus in shift workers
}

\author{
C J M Poole, A D Wright, $M$ Nattrass
}

\begin{abstract}
Objective-To determine whether the control of diabetes is different in insulin treated diabetic subjects who work shifts compared with those who do not work shifts and whether control is related to the type of shift worked.

Design-Prospective controlled study of 32 diabetic subjects working either regular days or shifts in a large car assembly factory. Insulin treated subjects who underwent a change in their pattern of shift work had diabetic control assessed before and six months after a change in shifts.

Main outcome measures-Random plasma glucose, serum fructosamine, and haemoglobin $A_{1}$ while at work.
\end{abstract}

Results-Diabetic control of insulin treated subjects who worked shifts was not significantly different from insulin treated subjects who worked days only. Diabetic control was poor in both groups and similar to that of diabetic subjects treated with oral hypoglycaemic agents. In those subjects that moved to a more rapidly rotating shift pattern there was a significant deterioration in control (serum fructosamine concentration before, 405 (SD 68); after, 481 (SD 90) $\mu \mathrm{mol} / 1, \mathrm{p}<0.01$ ).

Conclusions-The control of diabetes in insulin treated diabetic subjects who worked shifts was no worse than those who worked days only. Slowly rotating shifts were associated with better diabetic control than more rapidly rotating shifts.

Diabetic patients taking insulin may find difficulty with employment because of restrictions placed upon them for driving, working at heights, or working with potentially hazardous machinery. ${ }^{1}$ They may also be refused entry to schools of nursing ${ }^{2}$ or employment in public transport ${ }^{3}$ on the grounds of difficulty in adjusting to irregular hours or shifts. Until 1982

Department of Occupational Health, Rover, Longbridge, Birmingham B31 2TB

C J M Poole

Diabetic Clinic, General Hospital, Birmingham B4 6NH

A D Wright, $M$ Nattrass avoidance of shiftwork was supported by the British Diabetic Association but this view has been revised with the development of newer insulin regimens and better methods of monitoring blood glucose.

Few data exist on the effect of shift work upon diabetic control and advice given to diabetic patients is therefore empirical. We have studied the control of diabetes in a group of patients within one factory to determine firstly, whether control was worse in insulin treated subjects working shifts, and secondly, whether a change to a more rapidly rotating shift pattern would result in a deterioration in glycaemic control.

\section{Subjects and methods}

From the records of the Occupational Health Department of Rover, Longbridge, 98 diabetic subjects $(0.5 \%$ of the workforce) were identified. Of 34 subjects selected at random and given an explanation of the study 33 agreed to participate. Insulin treated subjects were subdivided into those who worked days only $(n=8)$ and those who worked shifts $(n=16)$. The groups were similar in age and duration of diabetes (mean age 48 and duration 12 years for shift workers; mean age 42 and duration 19 years for those working days only). For the purposes of the study day work was defined as working between 0800 and 1700 and shift work as a pattern of work involving successive rotating periods of one to four weeks of day and night work. Subjects on oral hypoglycaemic agents $(n=9$; mean age 57 years; mean duration of diabetes five years) working either days only or shifts formed the third group.

In the second part of the study 4000 employees underwent a change in the pattern of shiftwork due to increased production demands. A slowly rotating pattern of two weeks of days alternating with two weeks of nights was replaced by a more rapidly anticlockwise rotating three shift pattern-namely, a week of nights (2200 to 0600 ), a week of late days (1400 to 2200), and a week of early days (0600 to 1400). This provided an opportunity to study prospectively the effect of a change in shift pattern upon diabetic control in nine insulin treated subjects.

Blood was taken from non-fasting subjects while they were at work on two separate occasions, for measurement of plasma glucose, serum fructo- 
Table 1 Diabetic control in subjects on insulin working shifts $(n=16)$ or days only $(n=8)$, and in subjects taking oral hypoglycaemic drugs $(n=9)$

\begin{tabular}{|c|c|c|c|}
\hline & $\begin{array}{l}\text { Blood } \\
\text { glucose } \\
\text { (mmol/l) } \\
\text { Mean (SD) }\end{array}$ & 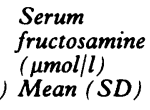 & $\begin{array}{l}H b A_{1}(\%) \\
\operatorname{Mean}(S D)\end{array}$ \\
\hline $\begin{array}{l}\text { Shifts on insulin } \\
\text { Days only on insulin } \\
\text { Oral hypoglycaemic drug }\end{array}$ & $\begin{array}{r}9.9(4.2) \\
11.6(3.7) \\
10.5(6.3)\end{array}$ & $\begin{array}{l}388(70) \\
422(66) \\
365(85)\end{array}$ & $\begin{array}{l}10.1(1.9) \\
10.5(1.8) \\
10.0(2.3)\end{array}$ \\
\hline
\end{tabular}

None of the differences between groups was statistically significant.

samine, and haemoglobin $\mathrm{A}_{1}\left(\mathrm{HbA}_{1}\right)$ concentrations. Samples were stored at $4^{\circ} \mathrm{C}$ and transported to the laboratory within 10 hours of venepuncture. In subjects who worked shifts two blood samples were obtained two to three weeks apart, on a different phase of the work shift-for example, on a night shift if taken on a day for those working fortnight about and on either a late or night shift if taken on an early shift for those working three shifts. Blood glucose was analysed by a glucose dehydrogenase method (Cobas Bio), with a coefficient of variation of $1.3-1.9 \%$; serum fructosamine was analysed by the nitrobluetetrazolium reduction method (Roche Diagnostics Ltd), with a coefficient of variation of $1 \cdot 6-2 \cdot 4 \%$, and glycosylated haemoglobin was analysed by electro-osmosis (Ciba-Corning Ltd) with a coefficient of variation of $5 \cdot 0-6 \cdot 7 \%$. The normal range in our laboratory for fructosamine is $210-280 \mu \mathrm{mol} / 1$ and for $\mathrm{HbA}_{1} 5 \cdot 6-8 \cdot 7 \%$. Statistical analysis was by Student's $t$ test using paired and unpaired data as appropriate. The study was approved by the research ethical committee of the Central Birmingham Health Authority.

\section{Results}

Diabetic control was not significantly different in insulin treated subjects working shifts compared with those who did not work shifts (table 1). Results in both insulin treated groups were similar to those in the group treated with oral hypoglycaemic agents.

In the nine insulin treated subjects who changed to a more rapidly rotating shift pattern there was a trend for diabetic control to worsen, with a significant increase in serum fructosamine (table 2).

Table 2 Diabetic control in subjects on insulin $(n=9)$ during a slowly changing and more rapidly changing shift pattern

\begin{tabular}{|c|c|c|c|}
\hline Shift pattern & $\begin{array}{l}\text { Blood } \\
\text { glucose } \\
\text { (mmol/l) } \\
\text { Mean (SD) }\end{array}$ & $\begin{array}{l}\text { Serum } \\
\text { fructosamine } \\
(\mu \text { mol/l) } \\
\text { Mean (SD) }\end{array}$ & $\begin{array}{l}H b A_{1}(\%) \\
\operatorname{Mean}(S D)\end{array}$ \\
\hline Slowly changing & $\begin{array}{l}9.4(3.8) \\
\text { NS }\end{array}$ & $\begin{array}{l}405(68) \\
p<0.01\end{array}$ & $\begin{array}{l}10 \cdot 4(1 \cdot 8) \\
\text { NS }\end{array}$ \\
\hline More rapidly changing & $11 \cdot 2(4 \cdot 2)$ & $481(90)$ & $10.9(1.9)$ \\
\hline
\end{tabular}

\section{Discussion}

No difference was found in the control of diabetes in insulin treated subjects who worked shifts compared with those who worked days only. This may be because the shift workers are a self selected group who are highly motivated to make the necessary changes to their regimens. Although the mean age and mean duration of diabetes in the two groups were not closely matched there is no reason to believe that these variables are related to diabetic control in this age group. Treatment regimens of the shift workers varied widely; one subject injected himself once daily, 12 twice daily, and three subjects four times daily. Only six subjects who took their insulin twice daily reversed the doses when working nights.

Despite this no difference was found in the frequency of hypoglycaemic episodes between shift and non-shift workers. Of those working shifts $50 \%$ reported hypoglycaemic episodes in the two weeks preceding the blood sample being taken (median number of episodes 1 (range 0-5) per subject per two weeks). In subjects not working shifts $\mathbf{5 0} \%$ reported hypoglycaemic episodes (median 1, range 0-11).

Diabetic control in both insulin treated groups was poor (serum fructosamine $>280 \mu \mathrm{mol} / 1$ or $\mathrm{HbA}_{1}>\mathbf{8 . 7 \%}$ ) but this has been reported whenever systematic study of insulin treated patients has been performed. Nevertheless, it was not significantly worse than in the subjects taking oral hypoglycaemic agents.

In those insulin treated subjects who changed from a slowly changing to a more rapidly changing shift pattern diabetic control tended to deteriorate. Most subjects received no guidance from their doctors on how best to adjust their insulin regimen to the new shift pattern and most kept to the same twice daily fixed regimen. One subject obtained improved control by changing to four injections a day, a regimen well suited to three shifts. A further problem of three shifts in this factory is that meal breaks are only 15 minutes. For speed of administration of insulin cartridge loaded pens are particularly useful.

The evidence presented here shows that diabetic subjects treated with insulin can work shifts and obtain as good a control of their diabetes without any increased risk of hypoglycaemia as can non-shift workers. This study has, however, highlighted the need for more flexibility and better education in the use of insulin for those diabetic employees who work shifts. Whether insulin is best taken twice or four times a day in shift workers remains to be determined.

We thank the nurses at Rover, especially Mrs Keys, Mrs Clarke, Mrs Green, and Mrs Moreton, for making this project possible and Miss Janet Smith, Department of Clinical Chemistry at the General Hospital for performing the assays. 
Requests for reprints to: Dr C J M Poole, Department of Occupational Health, Rover, Longbridge, Birmingham B31 2TB.

1 Waclawski ER. Employment and diabetes: a survey of the prevalence of diabetic workers known by occupational physicians, and the restrictions placed on diabetic workers in employment. Diabetic Medicine 1989;6:16-19.

2 Bagshaw E. Careers for diabetic girls in nursing. $B M J$ 1980;1:1227.
3 Engel HO. Employment problems of diabetics. Journal of the Royal Society of Medicine 1984;77:1061-62.

4 Greenwood RH, Raffle PAB. Diabetes mellitus. In: Edwards SC, McCallum RI, Taylor PJ, eds. Fitness to work: Medical aspects. Oxford: Oxford University Press, 1988:233-44.

5 Medical Advisory Committee, BDA. The employment of diabetics. Diabetic Medicine 1984;1:308.

Accepted 2 December 1991

\section{Vancouver style}

All manuscripts submitted to the $B r J$ Ind Med should conform to the uniform requirements for manuscripts submitted to biomedical journals (known as the Vancouver style).

The $\mathrm{Br} J$ Ind Med, together with many other international biomedical journals, has agreed to accept articles prepared in accordance with the Vancouver style. The style (described in full in $\mathrm{Br}$ Med J, 24 February 1979, p 532) is intended to standardise requirements for authors.

References should be numbered consecutively in the order in which they are first mentioned in the text by Arabic numerals above the line on each occasion the reference is cited (Manson ${ }^{1}$ confirmed other reports $\left.{ }^{2-5} \ldots\right)$. In future references to papers submitted to the $B r J$ Ind Med should include: the names of all authors if there are six or less or, if there are more, the first three followed by $e t$ al; the title of journal articles or book chapters; the titles of journals abbreviated according to the style of Index Medicus; and the first and final page numbers of the article or chapter.

Examples of common forms of references are:

1 International Steering Committee of Medical Editors. Uniform requirements for manuscripts submitted to biomedical journals. Br Med J 1979;1:532-5.

2 Soter NA, Wasserman SI, Austen KF. Cold urticaria: release into the circulation of histamine and eosino-phil chemotactic factor of anaphylaxis during cold challenge. N Engl J Med 1976;294:687-90.

3 Weinstein L, Swartz MN. Pathogenic properties of invading micro-organisms. In: Sodeman WA Jr, Sodeman WA, eds. Pathologic physiology: mechanisms of disease. Philadelphia: W B Saunders, 1974:457-72. 